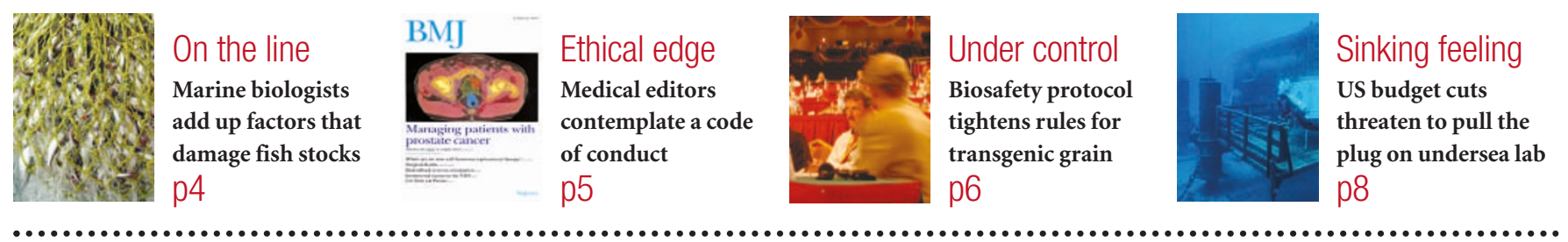

\title{
Doctors battle to contain AlDS epidemic as unrest engulfs Haiti
}

\section{Erika Check, Washington}

Even as looters roamed the streets of the Haitian capital last weekend, AIDS doctors in Port-au-Prince were still seeing their patients and dispensing medicine. Support workers were visiting mothers with AIDS in small, central villages. And clinics in the rural centre of the country were giving out life-saving HIV treatments, thanks to an emergency shipment of a six-week supply of medicine.

Around Haiti, AIDS doctors say that their work is more urgent than ever before. About $6 \%$ of Haiti's adults are infected with HIV the highest rate of infection in the Western Hemisphere. And some 30,000 Haitians die from the disease every year.

Determined researchers and physicians have established a network of clinics, community programmes and services to tackle the HIV problem at the grass roots. But in a country where the spread of AIDS has been driven by poverty and instability, the fresh political crisis threatens to fuel the epidemic. The turmoil is undermining programmes and studies that could yield crucial insight about what works best against the disease the same doctors who run the treatment and prevention efforts also conduct vital research into the dynamics of Haiti's AIDS epidemic.

"The situation here is very, very difficult," says Raul Boyle, the Haiti coordinator for UNAIDS, the Joint United Nations Programme on AIDS/HIV. "Everything is totally paralysed. I think that normalization and the possibility for agencies to restart their operations depends on having somelevel of security ensured by the international troops."

Boyle and other doctors say that the current crisis could worsen the Haitian AIDS epidemic in several ways. Roadblocks have disrupted food and medical shipments around the country, and doctors are worried that interruptions to treatment will nurture biological resistance to AIDS therapies.

Anarchy and violence are likely to lead to higher rates of rape, and women in isolated areas who have no access to food for their families might be driven to form partnerships with soldiers or truckers. Such alliances have spread AIDS in other parts of the world, says Ruth Berggren, an AIDS specialist at

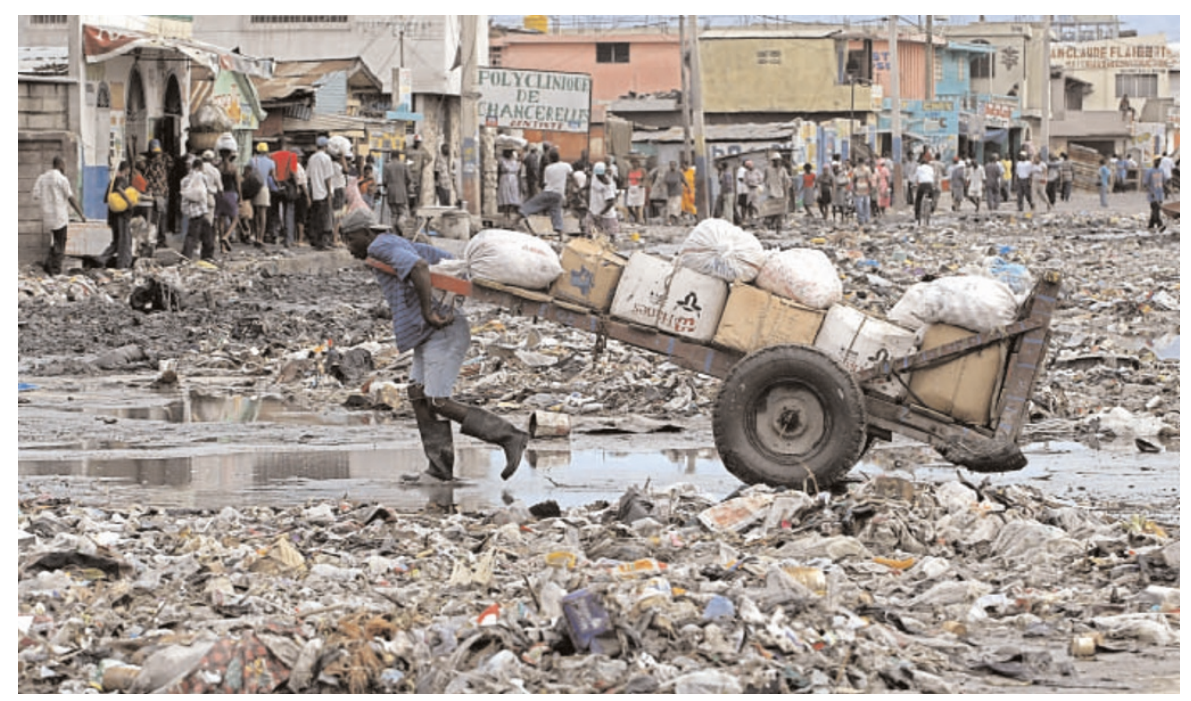

Out of control: chaos and uncertainty in Haiti threatens to exacerbate the nation's health problems.

Tulane University in New Orleans, Lousiana.

But physicians in Haiti are not giving up. Berggren works with MARCH, a group that uses mobile clinics to deliver food and medicine to 175,000 women around the central city of Mirebalais. It also runs a network of accompagnateurs — paid support workers who visit women with AIDS at their homes. Berggren says that roadblocks have forced MARCH to cancel some clinics. But she adds that accompagnateurs are still travelling on foot to check on their patients and to remind them to take their medicine. "This situation highlights how important the accompagnateur system is," Berggren says.

In Port-au-Prince, doctors at the country's oldest AIDS hospital were forced to close their doors when looting and violence broke out in the city. But they switched to a contingency plan that allows them to continue consulting with patients by phone. The hospital, the Haitian Study Group on Kaposi's Sarcoma and Opportunistic Infections (GHESKIO), is one of the main recipients of Haiti's US\$67million grant from the Global Fund to Fight AIDS, Tuberculosis and Malaria. The grant allowed GHESKIO to open 20 clinics around the country last year.

The money also pays for the distribution of anti-retroviral medicine to 1,800 patients.
Some of this reaches poor Haitians in the central part of the country through a network of clinics run by Partners in Health, based at Harvard University. Joia Mukherjee, medical director for the group, says that some of its clinics were closed two weeks ago when rebels seized control of towns where they were located. But he adds that doctors still saw 4,000 patients during that time.

Mukherjee says that poverty and political unrest are inextricably linked to the AIDS epidemic in Haiti and other countries hit hard by the disease. "If we give up on countries like Haiti, we're giving up on the epidemic," he says. "This kind of political unrest and structural violence is fomenting the epidemic worldwide."

GHESKIO’s director, Jean William Pape, echoes Mukherjee's determination. He hopes that the US administration will follow through with plans to send more money to AIDS programmes in Haiti. US officials announced such plans on 23 February, just six days before President Jean-Bertrand Aristide fled the country.

"We have worked through the dictatorship of the Duvaliers, the turmoil of the transition period, the coup d'état, the embargo and continuous civil unrest. This is one more hurdle that we will need to overcome," Pape says. 